\title{
The Contribution of Conceptual Frameworks to Knowledge Translation Interventions in Physical Therapy
}

Anne Hudon, Mathieu-Joël Gervais, Matthew Hunt

A. Hudon, PT, MSc, PhD candidate in Rehabilitation Sciences at the School of Rehabilitation, Université de Montréal, Montréal, Canada, and Centre for Interdisciplinary Research in Rehabilitation of Greater Montreal, Montréal, Canada. Mailing address: École de réadaptation, Faculté de Médecine, Université de Montréal, C.P. 6128, succ. Centre-Ville, Montréal (Qc) H3C 3J7 Canada. Address all correspondence to Ms Hudon at: anne.hudon@umontreal.ca.

M-J. Gervais, PhD Candidate at Université du Québec à Montréal, Montréal, Canada and CJMIU-UQÀM Chair on knowledge translation in the field of child and family welfare.

Hunt M, PhD, PT, Centre for Interdisciplinary Research in Rehabilitation of Greater Montreal, and Assistant Professor at School of Physical and Occupational Therapy, McGill University, Montréal, Canada.

Hudon, A., Gervais, M.-J. et Hunt, M. (2015). The contribution of conceptual frameworks to knowledge translation interventions in physical therapy. Physical therapy, 95(4), 630-639.

(C) 2014 American Physical Therapy Association 


\section{Acknowledgments}

Ms Hudon and Mr Gervais provided concept/idea/project design. All authors provided writing. Ms Hudon and Mr Gervais provided data collection and analysis and Ms Hudon ensured project management. All authors provided consultation (including review of manuscript before submission).

The authors wish to thank members of a journal club at McGill University for their valuable comments on a previous version of this manuscript. Anne Hudon is supported by a doctoral fellowship from the Fonds de recherche du Québec en santé (FRQ-S) and from the MENTOR program in collaboration with the Canadian Institutes of Health Research and the Quebec Research Rehabilitation Network (REPAR). Mathieu-Joël Gervais is supported by CJM-IUUQÀM Chair on knowledge translation in the field of child and family welfare and the KT Canada Student Fellowship and Training program. Matthew Hunt is supported by a Research

Scholar Award from FRQ-S. This research was funded by the Dominion of Canada General Insurance and administered by the Physiotherapy Foundation of Canada.

This is a pre-copyedited, author-produced version of an article accepted for publication in Physical Therapy following peer review. The version of record is available online at: https://academic.oup.com/ptj/article/95/4/630/2686409/The-Contribution-of-ConceptualFrameworks-to

DOI: $10.2522 / p t j .20130483$ 


\begin{abstract}
Context:

There is growing recognition of the importance of knowledge translation activities in physical therapy to ensure that research findings are integrated in clinical practice, and increasing numbers of knowledge translation interventions are being conducted. Although various frameworks have been developed to guide and facilitate the process of translating knowledge into practice, these tools have been infrequently used in physical therapy knowledge translation studies to date.
\end{abstract}

\title{
Problem and recommendation:
}

Knowledge translation in physical therapy implicates multiple stakeholders and environments, and involves numerous steps. In light of this complexity, the use of explicit conceptual frameworks by clinicians and researchers conducting knowledge translation interventions is associated with a range of potential benefits. In this article, we argue that such frameworks are important resources to promote the uptake of new evidence in physical therapy practice settings. We identify four key benefits associated with the use of conceptual frameworks in designing and implementing knowledge translation interventions. We also consider limits related to their use. We then evaluate a sample of five conceptual frameworks and consider how they address common barriers to knowledge translation in physical therapy. The goal of this analysis is to provide guidance to physical therapists seeking to identify a framework to support the design and implementation of a knowledge translation intervention. Finally, we illustrate the use of a conceptual framework through a case example. 


\section{Conclusion:}

Increased use of conceptual frameworks can have a positive impact on the field of knowledge translation in physical therapy and support the development and implementation of robust and effective knowledge translation interventions that help span the research-practice gap.

Keywords: physical therapy, knowledge translation, conceptual framework, rehabilitation 


\section{Body of the manuscript}

Notwithstanding significant expansion of its evidence base, multiple studies have demonstrated that the physical therapy (PT) profession has often failed to implement evidence-based practice $(\mathrm{EBP})^{1-3}$. Quality of care is diminished when patients do not receive services that are guided by the best available scientific evidence. In some instances, patients treated by physical therapists (PTs) receive insufficient, ineffective or potentially harmful treatment despite available scientific evidence that supports other clinical approaches ${ }^{4}$. Knowledge translation $(\mathrm{KT})^{5}$ interventions ${ }^{*}$ have been proposed as a key means to promote the uptake of research evidence into clinical practice and thus contribute to improved care for patients treated by $\mathrm{PTs}^{6,7}$. Despite this recognition of their importance, there remains debate and uncertainty regarding the best ways to design and implement $\mathrm{KT}$ interventions in healthcare, including $\mathrm{PT}^{8}$.

Bridging the research-practice gap in PT has proved difficult, in large part due to the complexity of designing and implementing successful KT interventions. An important challenge for PT KT relates to the different types of knowledge that need to be appraised and used to inform treatment decision-making. The knowledge base that underlies PT practice is multidimensional and requires PTs to master multiple types of knowledge if they are to provide optimal care for their patients $^{9,10}$. This knowledge goes beyond technical know-how, since human interactions and patient-clinician relationships are at the heart of the PT profession. The manual, hands-on dimension of the profession is also a significant aspect of practice that influences treatment outcomes. Thus, the knowledge needed to guide PT practice is comprised of multiple types of

\footnotetext{
* According to the Canadian Institutes of Health Research, KT interventions can be defined as iterative processes that include synthesis, dissemination and exchange between researchers and knowledge users in order to improve the usefulness and application of scientific knowledge into clinical practices.
} 
evidence drawn from different sources, including quantitative and qualitative research, as well as tacit and clinical knowledge ${ }^{11}$. As a result, knowledge coming from higher-order sources of evidence such as meta-analysis and systematic reviews is often insufficient on its own to guide decision-making related to best practices ${ }^{12}$. Such knowledge has to be combined with clinical observations, patient and family preferences, and clinical judgement in order that well-informed clinical decisions can be enacted ${ }^{13}$. Accounting for these diverse sources of knowledge is inherently challenging when implementing KT interventions ${ }^{14}$

Gaps between actual practice by PTs and the best available research evidence exist in multiple areas. These gaps range from evaluation methods for the cervical spine ${ }^{15}$, knowledge and use of low back pain clinical practice guidelines ${ }^{3}$, and outcome measures in paediatric $\mathrm{PT}^{16}$. Those wishing to span the research-practice gap will need to ask the following question: How can we design and implement a high-quality KT intervention that will be more likely to shift clinical practice? KT conceptual frameworks represent an important resource for those seeking to answer this question, and may be especially valuable guides to the design of effective KT interventions for researchers and clinicians with less KT experience ${ }^{17-19}$.

In this article we examine the potential contribution of $\mathrm{KT}$ conceptual frameworks to promote the uptake of new scientific evidence in PT practice settings. We argue that, when selected and used appropriately, such frameworks are important resources for designers of PT KT interventions. We highlight four key benefits of employing such frameworks, as well as reviewing some of the limits associated with their use. We then explore available KT frameworks in the rehabilitation and PT field, and analyze a sample of five frameworks in order to provide guidance to PT researchers and clinicians in the selection of a KT framework. Finally, we illustrate the use of a 
particular KT conceptual framework, the Ottawa Model of Research Use (OMRU), through a case example.

\section{The contributions of conceptual frameworks in PT KT interventions}

Conceptual frameworks consist of a set of linked concepts and propositions that are designed to draw attention to what is important regarding a phenomenon of interest ${ }^{20}$. Conceptual frameworks can thus help organize thinking, observation, and interpretation related to a particular phenomenon, and function as maps that enhance coherence of empirical inquiry ${ }^{5,21}$. Kitson and colleagues define a conceptual framework as "a set of variables and relationships that should be examined in order to understand a phenomenon"22(p.5). Thus, in the context of KT, a conceptual framework can be conceived as an overarching representation of key elements to use and acknowledge in the process of designing and implementing a KT intervention, and the interrelationships amongst these elements.

KT conceptual frameworks have been developed with the goal of helping to organize and understand the specific components, sequential stages, and contextual factors that need to be taken into account to facilitate successful implementation of a KT intervention, and to achieve desired outcomes. The use of conceptual frameworks can also guide project planners in assessing specific barriers to KT interventions, and develop strategies to decrease or eliminate these barriers. Similarly, they can support researchers and clinicians to identify specific facilitators, and select strategies to enhance them. Highlighting these impacts, several authors have advanced the view that KT activities related to rehabilitation and disability would benefit from increased use

of conceptual frameworks ${ }^{7,23}$. Despite the development of many KT frameworks over the past 
two decades, their uptake across healthcare disciplines, including PT, remains limited ${ }^{8}$. To gauge the use of conceptual frameworks for KT PT, we conducted a literature review in January 2014 using CINAHL, MEDLINE, and Embase databases, and keywords pertaining to KT and PT. We identified 8 PT KT studies ${ }^{16,24-30}$ that employed an explicit conceptual framework. This observation is consistent with previous reviews that documented infrequent use of conceptual frameworks in PT KT implementation studies ${ }^{31,32}$. Though infrequently used in PT KT to date, conceptual frameworks provide multiple benefits for the design of KT interventions. We highlight the following four benefits below: they help (1) map KT interventions; (2) support evaluation and attention to sustainability; (3) establish common ground and enhance communication between stakeholders; and (4) encourage transparency and clarity about KT methods.

\section{Mapping KT interventions to ensure that essential KT components are addressed}

Conceptual frameworks cue KT designers to attend to a wide range of considerations that are critical for implementing a successful $\mathrm{KT}$ intervention. This is an important contribution as it is not uncommon for KT interventions to target a single or only a few distinct individual barriers to the integration of evidence in clinical practice - but which ignore other significant contextual features ${ }^{33,34}$. Individual barriers include clinicians' receptivity or attitudes toward $\mathrm{EBP}^{35}$, their ability to identify relevant scientific knowledge ${ }^{36}$, or their capacity to integrate patient characteristics and preferences in the decision-making process ${ }^{37}$. Individual factors, however, are not the only or even most important barriers to KT. Multiple contextual features function as key influencers for the translation of knowledge in healthcare and have to be considered when designing a KT intervention ${ }^{38,39}$. For example, Rutten et al. identified how external and environmental determinants, including governmental policies and organizational structures and 
cultures, were important factors to consider in their efforts to promote the uptake of low back pain clinical guidelines in PT practice settings ${ }^{29}$. Conceptual frameworks can help researchers identify and plan for the diverse features that need to be accounted for in planning a robust KT intervention $^{7,19,21}$.

\section{Supporting efforts to evaluate impacts of the intervention and to promote sustainability}

The use of conceptual frameworks can also support efforts to evaluate the impacts of KT interventions. Given that KT conceptual frameworks typically include an evaluative aspect, those using such frameworks will be cued to implement evaluation in their KT interventions. Many KT conceptual frameworks go further and incorporate indicators to guide and structure the evaluation process, and help to appraise process and outcomes. Outcome evaluation might, for example, focus on changes of PT clinician behaviours, departmental or organizational functioning, or patient health and wellbeing. In line with a focus on evaluating outcomes, many KT conceptual frameworks also identify the need to address the issue of sustainability of the KT intervention, beginning in the early planning phases of a project. Attention to sustainability and evaluation are considerations that can increase the probability of sustained impact ${ }^{40,41}$. Users of KT frameworks will be primed to include these elements in their interventions.

\section{Establishing common ground and enhancing communication among stakeholders}

KT interventions frequently involve multiple stakeholders including researchers, clinicians, managers, and possibly patients. The potential diversity of stakeholders is illustrated by a KT study conducted by Brachaniec and colleagues on fibromyalgia that included representatives of patient groups, PT clinicians and researchers ${ }^{42}$. Stakeholders in KT interventions commonly have distinct (disciplinary and professional) backgrounds. As a result, they may not always share a 
common set of understandings and expectations upon which to base the development of a KT intervention $^{43}$. Use of a KT framework might help address these differences of expectations and priorities by incorporating a structure and strategies to help identify and discuss the diverse perspectives of stakeholders. In this way, using a framework to plan a KT intervention might help to establish common ground between stakeholders involved in the intervention.

Because conceptual frameworks clearly outline core steps and concepts of a KT intervention, their use may also help enhance quality of communication amongst stakeholders by providing shared terminology and making project steps and their rationales clearer for all involved. Establishing shared language that enhances communication has been identified as an important predictor of successful KT implementation and sustainability ${ }^{44}$. Increased communication can also contribute to a sense of shared "ownership" of the intervention. In turn, a greater sense of ownership will support an environment in which stakeholders feel welcome to offer suggestions for improvement, raise questions or concerns during the planning phase, and contribute to efforts to develop and sustain a shared action plan ${ }^{7,14}$.

\section{Encouraging transparency and clarity about KT methods}

The use of conceptual frameworks might also contribute to transparency about the implementation process of KT interventions. Currently, many authors of PT KT studies do not include a justification for their intervention design or their selection of specific KT strategies when they publish their results. Scott and colleagues reviewed eleven published PT KT interventions studies and found that all were missing important methodological details concerning the KT intervention implemented ${ }^{45}$. These authors also raised questions regarding an apparent over-reliance on educational strategies (i.e. educational meetings, workshops or 
brochures) without clear rationales offered for these approaches ${ }^{45}$. KT conceptual frameworks are not the only recourse for addressing these issues. They are, however, an important avenue to promote transparency and clarity about rationales and design decisions, and to improve the quality of KT reports. This assertion is consistent with research by Moher et al. who demonstrated that the use of formal methodological guidelines increases the quality of reports of randomized controlled trials ${ }^{46}$. Since frameworks function as scaffolding for KT interventions, they can assist manuscript reviewers and readers to understand the steps taken to select and implement particular KT strategies ${ }^{47}$. Readers will also be better able to judge the applicability of these findings to their local setting.

We have sought to demonstrate the benefits of employing KT conceptual frameworks and the roles they can play to increase the likelihood of implementing a successful KT intervention in PT.

\section{KT conceptual frameworks and their limits}

Despite the benefits outlined above, it is important to acknowledge that conceptual frameworks are not guarantors of successful KT interventions. Several limitations are associated with the use of KT conceptual frameworks ${ }^{21,48,49}$. We highlight here two primary limitations: the lack of empirical evidence demonstrating the value of KT conceptual frameworks, and risks associated with overreliance or misapplication of frameworks.

\section{Difficulty in demonstrating benefits of conceptual frameworks in KT intervention}

Appropriately enough given KT's focus on evidence, concern has been voiced regarding the evidence base underlying the use of KT frameworks. It has been noted that there is limited 
evidence demonstrating that KT interventions designed using a conceptual framework - or a specific theory - are superior to those that are $\operatorname{not}^{45}$. Since the value of using a range of conceptual frameworks has yet to be confirmed empirically, some authors have suggested the use of an approach based on common sense. This recommendation was advanced for the use of psychological theories to underpin behavioural change studies. A similar argument could be made in regards to $\mathrm{KT}$ frameworks as their evidence base is also $\operatorname{limited}^{50}$. While acknowledging the lack of empirical evidence on this question, we believe that the arguments in favour of conceptual frameworks discussed above are sufficient to warrant that researchers strongly consider their use. Limited knowledge about the relative effectiveness of using or not using conceptual frameworks may also be the product of difficulty in comparing between published studies due to limited methodological details available in most study reports ${ }^{51}$. Further studies assessing the comparative effectiveness of KT studies using conceptual frameworks versus pragmatic approaches would help to address this question ${ }^{31}$.

\section{Misapplication of conceptual frameworks}

Like all tools, KT conceptual frameworks can be misapplied or poorly implemented ${ }^{31,52}$. Perhaps the most important limitation of frameworks is that users may use them in a simplistic or mechanistic fashion and thus fail to develop an effective KT intervention. Such frameworks should be understood as guides, not recipes. Researchers and clinicians who plan to implement a KT intervention will benefit from reading widely about KT, conferring about their study with colleagues and mentors experienced in KT, and even taking courses related to KT science. Developing a broader understanding of the field of KT can thus help guard against overreliance on or formulaic use of frameworks that would limit creativity and responsiveness on the part of

KT implementers ${ }^{19,53}$. In this sense, conceptual frameworks will be most effective when used in 
a careful and reflexive manner, including an acknowledgement of their intended purpose and inherent limitations.

\section{Choosing a conceptual framework}

PT clinicians and researchers who wish to use a conceptual framework for their KT intervention have many options to choose between. Wilson and colleagues identified more than 30 frameworks and theoretical models that can be used to guide a KT intervention in healthcare ${ }^{54}$. To illustrate the diverse frameworks available for PT clinicians and researchers, we selected examples of KT frameworks used across PT, rehabilitation and healthcare domains. Twenty-six recent articles that use or describe the use of KT conceptual frameworks are presented in Table 1. Since we did not aim at performing a systematic review of the literature, this table consists of a sample of pertinent frameworks that are currently in use by KT implementers in healthcare.

\section{INSERT TABLE 1}

To date, there has been little analysis comparing the attributes of specific KT frameworks. There is continuing uncertainty about the relative strengths and limits of different KT frameworks, raising questions about which one would be the best to select for a given $\mathrm{KT}$ project ${ }^{21,55}$. Each framework draws attention to different components of the KT process. As a result, particular frameworks likely have strengths and weaknesses, and may be differently suited for application in particular contexts or to answer specific research questions ${ }^{56}$. 
To address this uncertainty, we sought to evaluate a sample of currently available frameworks for their potential application for KT in the PT field. To do so, we reviewed the more common barriers to EBP cited in current PT literature. We then associated, for each of these barriers, attributes of KT conceptual frameworks aiming to address them. Since more than 30 frameworks were identified through our literature search, we chose to analyse five KT conceptual frameworks from amongst those more commonly used in the context of rehabilitation and disability ${ }^{17}$ : Understanding-User-Context Framework (Five domain framework - 5-DF) ${ }^{57}$, Ottawa Model of Research Use (OMRU) $)^{58,59}$, Knowledge-to-Action Process Framework (KTA) ${ }^{18,20}$, Promoting Action on Research Implementation in Health Services Framework (PARiSH) ${ }^{60,61}$ and the Coordinated Implementation Model (CIM) ${ }^{62}$. The results of this exercise are presented in Table 2. Though only five example frameworks are presented here, the elements of the analysis presented in table 2 could be used by researchers and clinicians to assess how other frameworks address barriers to EBP in PT.

\section{INSERT TABLE 2}

The left column presents specific barriers to EBP found in the PT literature. The middle column describes attributes or characteristics of KT conceptual frameworks addressing these barriers. The five columns to the right present our analysis of the five selected frameworks. Two authors independently reviewed the original texts presenting detailed features of each of the five frameworks (AH and MJG). These evaluations were then compared, and a consensus was reached. A check mark was attributed to a framework when it presented the specific attribute 
listed in the middle column of Table 2 (i.e. when it addressed a specific barrier to EBP in PT). Thus, check marks indicate when a framework fulfills the characteristics of the second column.

As illustrated by Table 2, none of the five selected conceptual frameworks accounts for all the barriers to EBP implementation in PT. In that they address the greatest number of barriers to EBP in PT, the OMRU and the KTA frameworks appear to be promising frameworks for planning KT interventions in PT. To illustrate how such conceptual frameworks can be used, a case example is presented below in which the OMRU framework is being applied in a KT intervention.

\section{Applying the OMRU framework to a KT intervention project}

Our team is currently conducting a knowledge exchange project with ethics educators in PT and Occupational Therapy (OT) programs across Canada. This project originated from an identified gap in the literature about what is actually and what should be taught in Canadian university ethics curricula $^{63,64}$. Originally, a straightforward KT strategy was chosen: a one-day workshop bringing together all PT and OT ethics educators in Canada. In the early phases of the project, however, our team identified the need to develop a more sophisticated KT approach and elected to adopt the OMRU framework to structure the intervention. The OMRU was chosen because it encompasses all stages of a KT intervention (from conception and tailoring of knowledge to evaluation of outcomes). Hence, this framework is particularly useful to develop a more rigorous KT design structure. It also helped the whole team (researchers, ethics educators and program coordinators) understand and follow each step of the KT process. The framework provided useful guidance for selecting appropriate strategies for implementing our KT intervention. It also drew attention to how organizational and contextual barriers (e.g., regulations and policies, 
remuneration systems, lack of time, etc.), as well as barriers related to individual characteristics (e.g., awareness, attitudes, concerns, current practices, etc.) can influence the KT process. Finally, and unlike most other KT conceptual framework, the OMRU highlighted core elements of knowledge exchange that needed to be addressed in order to support an interactive process ${ }^{65}$. As a result, many significant elements were changed or added to our original KT intervention planning. We highlight key changes below.

First, when looking at the "potential adopters" section of the framework, we realized that we lacked information about who was teaching ethics content in the different Canadian programs, and under which conditions. We thus developed a survey to learn about ethics teachers and what they taught. With this survey, we learned that most educators did not have any post-graduate training in ethics $(65 \%)$ and that most were not full time university teachers ${ }^{64}$. This changed the way we framed our one-day workshop, putting more emphasis on practical and concrete day-today problems in ethics teaching. To learn about participants' expectations, we also solicited input prior to the workshop and adjusted the planning in light of what we heard (including adding more time for open discussion and networking). The OMRU also guided our team toward integrating longer-lasting interventions to ensure sustainability. We thus developed a "wiki platform". A "wiki" is a collaborative web based tool that allows groups to jointly create and exchange knowledge on a given subject ${ }^{66}$. The use of the wiki aims to promote continued engagement of participants after the workshop is completed, and to create ongoing exchanges between participants.

Finally, the OMRU framework facilitated the identification of key steps for evaluation of the KT intervention, including use of the wiki and follow-up interviews with participants to explore 
whether they had changed their teaching as a result of the KT intervention. Overall, using the OMRU framework helped our team to select and tailor appropriate strategies to carry out our KT project. For each of the specific barriers identified, a strategy was chosen to address it. Evaluation methods were also integrated in the project design from an early stage of its development. This case example illustrates how the use of the OMRU helped our team navigate smoothly through the progression of a KT project.

\section{Conclusion}

In sum, KT conceptual frameworks have the potential to promote systematic and well-planned KT interventions in PT. It has been argued that guidance is currently lacking "to help healthcare researchers, practitioners, or managers make decisions about what implementation strategies to use, in which contexts, and with what groups of stakeholders"19(p.S79). Indeed, planning how to integrate research into practice has been described as a "black box" $"$. Conceptual frameworks for PT KT can help signpost the process of KT design and implementation, thus helping to plan, implement and evaluate $\mathrm{KT}$ interventions ${ }^{67}$.

Conceptual frameworks do not, however, take away the need for thoughtful and creative planning and design of KT interventions. Those seeking to apply a conceptual framework will benefit from training in KT science and mentoring from experienced colleagues to help them optimize the KT process and avoid poor quality interventions. They will also need to carefully examine available KT frameworks in order to select a robust framework that corresponds with the reality of their project and the implementation context. In order to support this selection process, we have analyzed a sample of five of the more commonly used conceptual frameworks and considered 
whether they address key barriers to evidence uptake in PT. Conceptual frameworks can help structure the design and implementation process in ways that promote successful KT interventions. Such frameworks are an important resource to advancing EBP in PT and bridging the lingering research-practice gap.

\section{Acknowledgements}

The authors wish to thank members of a journal club at McGill University for their valuable comments on a previous version of this manuscript. Anne Hudon is supported by a doctoral fellowship from the Fonds de recherche du Québec en santé (FRQ-S) and from the MENTOR program in collaboration with the Canadian Institutes of Health Research and the Quebec Research Rehabilitation Network (REPAR). Mathieu-Joël Gervais is supported by CJM-IUUQÀM Chair on knowledge translation in the field of child and family welfare and the KT Canada Student Fellowship and Training program. Matthew Hunt is supported by a Research

Scholar Award from FRQ-S. This research was funded by the Dominion of Canada General Insurance and administered by the Physiotherapy Foundation of Canada. 
Tables 
Table 1: Examples of conceptual frameworks from published articles

\begin{tabular}{|c|c|}
\hline Reference & Examples of conceptual frameworks or theories \\
\hline \multicolumn{2}{|l|}{ Physical Therapy } \\
\hline Bekkering et al., 2003 & 10-step model for inducing change in professional behaviour \\
\hline Harting et al., 2009 & Diffusion of innovation (DOI) \\
\hline Ketelaar et al., 2008 & 10-step model for inducing change in professional behaviour \\
\hline Rivard et al., 2010 & 10-step model for inducing change in professional behaviour \\
\hline $\begin{array}{l}\text { Rutten et al., 2009, } 2013 \text { and } \\
2014\end{array}$ & $\begin{array}{l}\text { GUideline Implimentation DEterminant framework (GUIDE) and the } \\
\text { Intervention mapping framework that are based on different theories such } \\
\text { as: Active learning theory, Theory of planned behaviour (TPB), Goal } \\
\text { setting theory, etc. }\end{array}$ \\
\hline Sinden \& MacDermid, 2014 & Knowledge-To-Action Process framework (KTA) \\
\hline Zidarov et al., 2013 & Ottawa Model of Research Use (OMRU) \\
\hline \multicolumn{2}{|l|}{ Rehabilitation } \\
\hline Colquhoun et al., 2010 & $\begin{array}{l}\text { DOI, Promoting Action on Research Implementation in Health } \\
\text { Services framework (PARiSH), TPB }\end{array}$ \\
\hline MacDermid et al., 2006 & Problem based learning model (PBL) \\
\hline Menon et al., 2009 & OMRU \\
\hline Metzler \& Metz, 2010 & KTA \\
\hline \multicolumn{2}{|l|}{ Healthcare } \\
\hline Brachaniec et al., 2009 & $\begin{array}{l}\text { EPICOT framework: Evidence, Population, Intervention, Comparison } \\
\text { group, Outcomes, and Time }\end{array}$ \\
\hline Damshroder et al., 2009 & $\begin{array}{l}19 \text { frameworks discussed (e.g., Conceptual Framework for Transferring } \\
\text { Research to Practice, Conceptual Model for Implementation Effectiveness, } \\
\text { etc.) and one model proposed: Consolidated Framework for } \\
\text { Implementation Research (CFIR) }\end{array}$ \\
\hline Davies et al., 2010 & $\begin{array}{l}25 \text { theories discussed by authors (e.g., PRECEDE model, DOI, } \\
\text { Information overload, Social cognitive theory, Dual task theory, Stages of } \\
\text { change, Four-step-intervention, etc.) }\end{array}$ \\
\hline Estrabrook et al., 2006 & $\begin{array}{l}18 \text { conceptual models presented (e.g., Readiness-to-change model, Social } \\
\text { influences theory, Dual core model of the innovation, Desperation reaction } \\
\text { model, etc.) }\end{array}$ \\
\hline French et al., 2012 & Theoretical domains framework (TDF) \\
\hline Graham et al., 2007 & $\begin{array}{l}\text { Total of } 31 \text { models/framework identified (e.g., KTA, DOI, Coordinated } \\
\text { implementation model, PARiSH) }\end{array}$ \\
\hline Grol et al., 2007 & $\begin{array}{l}\text { Exploration of numerous theories (e.g., Process theories, Readiness-to- } \\
\text { change model, Social learning theory, Theory of contracting, Elaboration } \\
\text { Likelihood Model, etc.) }\end{array}$ \\
\hline Ilott et al., 2013 & CFIR \\
\hline Majdazeh et al., 2008 & $\begin{array}{l}\text { The Tehran University of Medical Sciences Knowledge Translation Cycle } \\
\text { (TUMS) }\end{array}$ \\
\hline Michie et al., 2011 & The Behaviour Change Wheel (BCW) \\
\hline Sales et al., 2002 & $\begin{array}{l}\text { DOI, Social Cognitive Theory, Social Influence Theory, PRECEDE } \\
\text { model, PARIHS }\end{array}$ \\
\hline Stevenson et al., 2006 & Structure-Process-Outcome model \\
\hline Sudsawad, 2007 & $\begin{array}{l}\text { Understanding-User-Context Framework (Five domain framework), } \\
\text { OMRU, KTA, PARiSH, The Coordinated Implementation Model } \\
\text { (CIM), The Stetler Model of Research Utilization }\end{array}$ \\
\hline Wilson et al., 2010 & $\begin{array}{l}33 \text { frameworks discussed by authors (e.g., TUMS, Five domain } \\
\text { framework, etc.) }\end{array}$ \\
\hline
\end{tabular}


I ne ine irameworks in void are analyzed in tne ionowing sectons. 
Table 2: Analysis of five KT conceptual frameworks

\begin{tabular}{|c|c|c|c|c|c|c|}
\hline \multirow{2}{*}{$\begin{array}{l}\text { Barriers to evidence-based } \\
\text { practice (EBP) in PT }\end{array}$} & \multirow{2}{*}{$\begin{array}{l}\text { Attributes of KT conceptual } \\
\text { frameworks }\end{array}$} & \multicolumn{5}{|c|}{ Conceptual frameworks analysed } \\
\hline & & $\mathrm{CIIM}^{62}$ & DF $^{57}$ & $\underset{18,20}{\text { KTA }}$ & $\underset{58,59}{\text { OMRU }}$ & $\underset{60,61}{\text { PARiSH }}$ \\
\hline \multicolumn{7}{|l|}{ General barriers to implementation } \\
\hline $\begin{array}{l}\text { Lack of details about the whole } \\
\text { process and stages surrounding } \\
\text { the KT intervention }\end{array}$ & $\begin{array}{l}\text { Encompass all stages of a KT } \\
\text { intervention (from conception or } \\
\text { tailoring of knowledge to } \\
\text { evaluation of outcomes) }\end{array}$ & & & $\checkmark$ & $\checkmark$ & \\
\hline $\begin{array}{l}\text { Use of passive strategies less } \\
\text { effective than active strategies }{ }^{69}\end{array}$ & $\begin{array}{l}\text { Provide guidance in choosing } \\
\text { appropriate strategies for } \\
\text { implementation }\end{array}$ & $\checkmark$ & $\checkmark$ & $\checkmark$ & $\boldsymbol{V}$ & \\
\hline \multicolumn{7}{|l|}{$\begin{array}{l}\text { Organizational and contextual } \\
\text { barriers }\end{array}$} \\
\hline $\begin{array}{l}\text { Lack of attention given to } \\
\text { organisational context and } \\
\text { culture }^{38}\end{array}$ & $\begin{array}{l}\text { Acknowledge the importance of } \\
\text { the context and organisational } \\
\text { structure surrounding the project } \\
\text { (not only the individual barriers) }\end{array}$ & $\checkmark$ & $\checkmark$ & $\checkmark$ & $\checkmark$ & $\checkmark$ \\
\hline $\begin{array}{l}\text { Lack of time for } \\
\text { implementation }\end{array}$ & $\begin{array}{l}\text { Take into consideration time as a } \\
\text { specific barrier to implementation }\end{array}$ & & & & $\checkmark$ & \\
\hline $\begin{array}{l}\text { Lack of consideration for } \\
\text { availability of equipment, } \\
\text { financial resources, cost-sharing } \\
\text { issues and support from } \\
\text { colleagues and managers in } \\
\text { implementing new evidence }^{71}\end{array}$ & $\begin{array}{l}\text { Take into account the human, } \\
\text { material and financial resources } \\
\text { available (e.g., availability of } \\
\text { space and equipment) and support } \\
\text { from colleagues and managers / } \\
\text { feasibility }\end{array}$ & $\boldsymbol{V}$ & $\checkmark$ & $\checkmark$ & $\boldsymbol{V}$ & $\checkmark$ \\
\hline \multicolumn{7}{|l|}{$\begin{array}{l}\text { Barriers related to individual } \\
\text { characteristics }\end{array}$} \\
\hline $\begin{array}{l}\text { - Minimal attention given to } \\
\text { patients' and therapists' } \\
\text { preferences }^{68}\end{array}$ & $\begin{array}{l}\text { Understand expectations and } \\
\text { needs of patients and } \\
\text { professionals and the importance } \\
\text { of the values of the main } \\
\text { stakeholders }\end{array}$ & $\boldsymbol{V}$ & $\checkmark$ & $\checkmark$ & $\checkmark$ & $\checkmark$ \\
\hline $\begin{array}{l}\text { Lack of consideration for users' } \\
\text { abilities and motivation to } \\
\text { change and personal } \\
\text { characteristics (degree, age, } \\
\text { etc.) }\end{array}$ & $\begin{array}{l}\text { Consider characteristics of } \\
\text { potential users in the choice of } \\
\text { implementation strategies }\end{array}$ & $\checkmark$ & $\checkmark$ & $\checkmark$ & $\checkmark$ & \\
\hline $\begin{array}{l}\text { Lack of role clarity between } \\
\text { professionals }\end{array}$ & $\begin{array}{l}\text { Clarify roles of all stakeholders } \\
\text { involved in the KT intervention }\end{array}$ & $\checkmark$ & & & & $\checkmark$ \\
\hline $\begin{array}{l}\text { Lack of confidence and limited } \\
\text { skills to identify, appraise, read } \\
\text { and use evidence }\end{array}$ & $\begin{array}{l}\text { Take into consideration the skills } \\
\text { of users and help facilitate the } \\
\text { appraisal of evidence }\end{array}$ & $\boldsymbol{V}$ & $\checkmark$ & $\checkmark$ & $\checkmark$ & $\checkmark$ \\
\hline \multicolumn{7}{|l|}{$\begin{array}{l}\text { Barriers related to interactions } \\
\text { between creators/implementers and } \\
\text { users }\end{array}$} \\
\hline $\begin{array}{l}\text { Lack of consideration for the } \\
\text { interactions between knowledge } \\
\text { creators /implementers and } \\
\text { knowledge users }{ }^{73,74}\end{array}$ & $\begin{array}{l}\text { Take into account the interaction } \\
\text { parameters (type, frequency, } \\
\text { structure, etc.) between } \\
\text { knowledge creators/implementers } \\
\text { and knowledge users }\end{array}$ & & $\checkmark$ & $\checkmark$ & $\checkmark$ & \\
\hline \multicolumn{7}{|l|}{$\begin{array}{l}\text { Barriers related to scientific } \\
\text { evidence }\end{array}$} \\
\hline $\begin{array}{l}\text { - } \text { Research evidence not always } \\
\text { relevant or applicable to }\end{array}$ & $\begin{array}{l}\text { Consider the utility and relevance } \\
\text { of evidence in relation to the }\end{array}$ & $\checkmark$ & $\checkmark$ & $\checkmark$ & $\checkmark$ & $\checkmark$ \\
\hline
\end{tabular}




\begin{tabular}{|c|c|c|c|c|c|c|}
\hline practice setting $^{72}$ & $\begin{array}{l}\text { specific context of } \\
\text { implementation }\end{array}$ & & & & & \\
\hline $\begin{array}{l}\text { Lack of confidence in the } \\
\text { validity and credibility of } \\
\text { research findings }\end{array}$ & $\begin{array}{l}\text { Consider the validity and } \\
\text { credibility of research findings }\end{array}$ & $\checkmark$ & $\checkmark$ & $\checkmark$ & $\checkmark$ & $\checkmark$ \\
\hline $\begin{array}{l}\text { Evidence not presented in } \\
\text { formats that facilitate uptake by } \\
\text { clinicians (no summary, use of } \\
\text { overly technical language, } \\
\text { etc.) }\end{array}$ & $\begin{array}{l}\text { Consider how to format evidence } \\
\text { to facilitate uptake by clinicians } \\
\text { or other users }\end{array}$ & $\checkmark$ & $\checkmark$ & $\checkmark$ & $\checkmark$ & $\checkmark$ \\
\hline $\begin{array}{l}\text { Lack of consideration for the } \\
\text { co-creation of knowledge to } \\
\text { implement, and for the } \\
\text { experiential and tacit } \\
\text { knowledge of users }{ }^{72}\end{array}$ & $\begin{array}{l}\text { Acknowledge the co-creation of } \\
\text { knowledge and the value of } \\
\text { experiential and tacit knowledge }\end{array}$ & & & $\checkmark$ & & \\
\hline \multicolumn{7}{|l|}{ Barriers to evaluating intervention } \\
\hline $\begin{array}{l}\text { Lack of evaluative and } \\
\text { monitoring strategies to assess } \\
\text { the outcomes of intervention }\end{array}$ & $\begin{array}{l}\text { Incorporate an evaluative } \\
\text { component of the intervention } \\
\text { (including outcome measures) }\end{array}$ & $\checkmark$ & & $\checkmark$ & $\checkmark$ & \\
\hline \multicolumn{7}{|l|}{$\begin{array}{l}\text { Barriers to the sustainability of } \\
\text { intervention }\end{array}$} \\
\hline $\begin{array}{l}\text { Lack of follow-up strategies } \\
\text { after the completion of the KT } \\
\text { intervention }\end{array}$ & $\begin{array}{l}\text { Incorporate a follow-up } \\
\text { component to insure sustainability } \\
\text { of the intervention }\end{array}$ & $\checkmark$ & & $\checkmark$ & & \\
\hline Total /16: & & 12 & 10 & 14 & 13 & 8 \\
\hline
\end{tabular}




\section{References}

1. Schreiber J, Stern P. A review of the literature on evidence-based practice in physical therapy. The Internet Journal of Allied Health Sciences and Practice. 2005;3(4).

2. Jette AM. The peril of inadequate evidence. Physical therapy. 2005;85(4):302-303.

3. Derghazarian T, Simmonds MJ. Management of low back pain by physical therapists in quebec: how are we doing? Physiotherapy Canada. 2011;63(4):464-473.

4. McGlynn EA, Asch SM, Adams J, et al. The quality of health care delivered to adults in the United States. New England journal of medicine. 2003;348(26):2635-2645.

5. Graham ID, Tetroe J, Group KTR. Some theoretical underpinnings of knowledge translation. Academic Emergency Medicine. 2007;14:936-941.

6. Gross DP, Lowe A. Evaluation of a knowledge translation initiative for physical therapists treating patients with work disability. Disability \& Rehabilitation. 2009;31(11):871-879.

7. Zidarov D, Thomas A, Poissant L. Knowledge translation in physical therapy: from theory to practice. Disability \& Rehabilitation. 2013(0):1-7.

8. Grimshaw J, Thomas R, MacLennan G, et al. Effectiveness and efficiency of guideline dissemination and implementation strategies. 2004.

9. Jensen GM, Gwyer J, Shepard KF, Hack LM. Expert practice in physical therapy. Physical therapy. 2000;80(1):28-43.

10. Shepard KF, Hack LM, Gwyer J, Jensen GM. Describing expert practice in physical therapy. Qualitative Health Research. 1999;9(6):746-758.

11. Dijkers MP, Murphy SL, Krellman J. Evidence-based practice for rehabilitation professionals: concepts and controversies. Archives of physical medicine and rehabilitation. 2012;93(8):S164-S176.

12. DiCenso A, Bayley L, Haynes RB. Accessing pre-appraised evidence: fine-tuning the 5S model into a 6S model. Evidence based nursing. 2009;12(4):99-101.

13. Bithell C. Evidence-based Physiotherapy: Some thoughts on 'best evidence'. Physiotherapy. 2000;86(2):58-59.

14. Graham I, Logan J, Tetroe J. Models of implementation in nursing. In: Cullum N, Ciliska D, Haynes R, Marks S, eds. Evidence-based nursing. Oxford: Blackwell Publishing Ltd; 2008:231-243.

15. MacDermid JC, Walton DM, Côté P, Santaguida PL, Gross A, Carlesso L. Suppl 4: Use of Outcome Measures in Managing Neck Pain: An International Multidisciplinary Survey. The open orthopaedics journal. 2013;7:506.

16. Ketelaar M, Russell DJ, Gorter JW. The challenge of moving evidence-based measures into clinical practice: lessons in knowledge translation. Physical \& occupational therapy in pediatrics. 2008;28(2):191-206.

17. Sudsawad P. Knowledge translation: Introduction to models, strategies, and measures. Austin, TX: Southwest Educational Development Laboratory, National Center for the Dissemination of Disability Research. Retrieved April. 2007;14:2008.

18. Graham ID, Logan J, Harrison MB, et al. Lost in knowledge translation: time for a map? Journal of continuing education in the health professions. 2006;26(1):13-24.

19. Rycroft-Malone J. Theory and knowledge translation: setting some coordinates. Nursing Research. 2007;56(4):S78-S85.

20. Graham ID, Tetroe J. Some theoretical underpinnings of knowledge translation. Academic Emergency Medicine. 2007;14(11):936-941.

21. Francis J. Designing theoretically-informed implementation interventions. Implementation Science. 2006;1:4-? 
22. Kitson AL, Rycroft-Malone J, Harvey G, McCormack B, Seers K, Titchen A. Evaluating the successful implementation of evidence into practice using the PARiHS framework: theoretical and practical challenges. Implement Sci. 2008;3(1):1.

23. Metzler MJ, Metz GA. Translating knowledge to practice: An occupational therapy perspective. Australian Occupational Therapy Journal. 2010;57(6):373-379.

24. Bekkering G, Engers A, Wensing M, et al. Development of an implementation strategy for physiotherapy guidelines on low back pain. Australian Journal of Physiotherapy. 2003;49(3):208.

25. Rivard LM, Russell DJ, Roxborough L, Ketelaar M, Bartlett DJ, Rosenbaum P. Promoting the use of measurement tools in practice: a mixed-methods study of the activities and experiences of physical therapist knowledge brokers. Physical therapy. 2010;90(11):1580-1590.

26. Harting J, Rutten G, Rutten S, Kremers S. A qualitative application of the diffusion of innovations theory to examine determinants of guideline adherence among physical therapists. Phys Ther. 2009;89(3):221 - 232.

27. Rutten G, Harting J, Bartholomew L, Schlief A, Oostendorp R, de Vries N. Evaluation of the theory-based Quality Improvement in Physical Therapy (QUIP) programme: a onegroup, pre-test post-test pilot study. BMC Health Serv Res. 2013;13:194.

28. Rutten G, Kremers S, Rutten S, Harting J. A theory-based cross-sectional survey demonstrated the important role of awareness in guideline implementation. J Clin Epidemiol. 2009;62(2):167 - 176.

29. Rutten G, Harting J, Bartholomew L, et al. Development of a theory- and evidence-based intervention to enhance implementation of physical therapy guidelines for the management of low back pain. Archives of Public Health. 2014;72(1):1.

30. Sinden K, MacDermid JC. Does the knowledge-to-action (KTA) framework facilitate physical demands analysis development for firefighter injury management and return-towork planning? Journal of occupational rehabilitation. 2013:1-14.

31. Colquhoun HL, Letts LJ, Law MC, MacDermid JC, Missiuna CA. A scoping review of the use of theory in studies of knowledge translation. Canadian Journal of Occupational Therapy. 2010;77(5):270-279.

32. Davies P, Walker AE, Grimshaw JM. A systematic review of the use of theory in the design of guideline dissemination and implementation strategies and interpretation of the results of rigorous evaluations. Implement Sci. 2010;5:14.

33. Grimshaw JM, Eccles MP, Lavis JN, Hill SJ, Squires JE. Knowledge translation of research findings. Implement Sci. 2012;7(1):50.

34. Rycroft-Malone J. Evidence - informed practice: from individual to context. Journal of Nursing Management. 2008;16(4):404-408.

35. Shuval K, Berkovits E, Netzer D, et al. Evaluating the impact of an evidence - based medicine educational intervention on primary care doctors' attitudes, knowledge and clinical behaviour: a controlled trial and before and after study. Journal of evaluation in clinical practice. 2007;13(4):581-598.

36. Boissel J-P, Amsallem E, Cucherat M, Nony P, Haugh MC. Bridging the gap between therapeutic research results and physician prescribing decisions: knowledge transfer, a prerequisite to knowledge translation. European journal of clinical pharmacology. 2004;60(9):609-616. 
37. Giguere A, Légaré F, Grad R, et al. Decision boxes for clinicians to support evidencebased practice and shared decision making: the user experience. Implement Sci.

2012;7:72.

38. Salbach NM, Jaglal SB, Korner-Bitensky N, Rappolt S, Davis D. Practitioner and organizational barriers to evidence-based practice of physical therapists for people with stroke. Physical Therapy. 2007;87(10):1284-1303.

39. Marchionni C, Ritchie J. Organizational factors that support the implementation of a nursing Best Practice Guideline. Journal of nursing management. 2008;16(3):266-274.

40. Stirman SW, Kimberly J, Cook N, Calloway A, Castro F, Charns M. The sustainability of new programs and innovations: a review of the empirical literature and recommendations for future research. Implement Sci. 2012;7:17.

41. Tricco AC, Cogo E, Ashoor H, et al. Sustainability of knowledge translation interventions in healthcare decision-making: protocol for a scoping review. BMJ Open. January 1, 2013 2013;3(5).

42. Brachaniec M, DePaul V, Elliott M, Moore L, Sherwin P. Partnership in action: an innovative knowledge translation approach to improve outcomes for persons with fibromyalgia. Physiotherapy Canada. 2009;61(3):123-127.

43. Zwarenstein M, Reeves S. Knowledge translation and interprofessional collaboration: Where the rubber of evidence - based care hits the road of teamwork. Journal of Continuing Education in the Health Professions. 2006;26(1):46-54.

44. Palinkas LA, Aarons GA, Chorpita BF, Hoagwood K, Landsverk J, Weisz JR. Cultural Exchange and the Implementation of Evidence-Based Practices Two Case Studies. Research on Social Work Practice. 2009;19(5):602-612.

45. Scott SD, Albrecht L, O'Leary K, et al. Systematic review of knowledge translation strategies in the allied health professions. Implement Sci. 2012;7(1):70-70.

46. Moher D, Jones A, Lepage L, Group C. Use of the CONSORT statement and quality of reports of randomized trials: a comparative before-and-after evaluation. Jama. 2001;285(15):1992-1995.

47. Tong A, Sainsbury P, Craig J. Consolidated criteria for reporting qualitative research (COREQ): a 32-item checklist for interviews and focus groups. International Journal for Quality in Health Care. 2007;19(6):349-357.

48. Grol RP, Bosch MC, Hulscher ME, Eccles MP, Wensing M. Planning and studying improvement in patient care: the use of theoretical perspectives. Milbank Quarterly. 2007;85(1):93-138.

49. Sales A, Smith J, Curran G, Kochevar L. Models, strategies, and tools: Theory in implementing evidence-based findings into health care practice. Journal of General Internal Medicine. February 2006;21(SUPPL. 2):S43-S49.

50. Bhattacharyya O, Reeves S, Garfinkel S, Zwarenstein M. Designing theoreticallyinformed implementation interventions: Fine in theory, but evidence of effectiveness in practice is needed. Implement Sci. 2006;1(5):1-3.

51. LaRocca R, Yost J, Dobbins M, Ciliska D, Butt M. The effectiveness of knowledge translation strategies used in public health: a systematic review. BMC Public Health. 2012;12(1):751.

52. Mendel P, Meredith LS, Schoenbaum M, Sherbourne CD, Wells KB. Interventions in organizational and community context: a framework for building evidence on dissemination and implementation in health services research. Administration and Policy in Mental Health and Mental Health Services Research. 2008;35(1-2):21-37. 
53. Oxman AD, Fretheim A, Flottorp S. The OFF theory of research utilization. Journal of Clinical Epidemiology. 2005;58(2):113-116.

54. Wilson PM, Petticrew M, Calnan MW, Nazareth I. Disseminating research findings: what should researchers do? A systematic scoping review of conceptual frameworks. Implementation Science. 2010;5(1):91.

55. Estabrooks CA, Thompson DS, Lovely JJE, Hofmeyer A. A guide to knowledge translation theory. Journal of Continuing Education in the Health Professions. 2006;26(1):25-36.

56. French SD, Green SE, O'Connor DA, et al. Developing theory-informed behaviour change interventions to implement evidence into practice: a systematic approach using the Theoretical Domains Framework. Implementation Science. 2012;7(1):38.

57. Jacobson N, Butterill D, Goering P. Development of a framework for knowledge translation: understanding user context. Journal of health services research \& policy. 2003;8(2):94-99.

58. Hogan DL, Logan J. The Ottawa model of research use: a guide to clinical innovation in the NICU. Clinical Nurse Specialist. 2004;18(5):255-261.

59. Logan J, Graham ID. Toward a comprehensive interdisciplinary model of health care research use. Science communication. 1998;20(2):227-246.

60. Kitson A, Harvey G, McCormack B. Enabling the implementation of evidence based practice: a conceptual framework. Quality in Health care. 1998;7(3):149-158.

61. Rycroft-Malone J, Kitson A, Harvey G, et al. Ingredients for change: revisiting a conceptual framework. Quality and Safety in Health Care. 2002;11(2):174-180.

62. Lomas J. Retailing research: increasing the role of evidence in clinical services for childbirth. The Milbank Quarterly. 1992;71(3):439-475.

63. Hudon A, Laliberte M, Hunt M, et al. What place for ethics? An overview of ethics teaching in occupational therapy and physiotherapy programs in Canada. Disabil Rehabil. Jul 182013.

64. Laliberté M, Hudon A, Hunt M, Williams-Jones B, Erhmann Feldman D, Mazer B. Just a soft skill? An in depth analysis of ethics teaching in Canadian OT and PT programs. Under preparation.

65. Graham ID, Logan J. Innovations in knowledge transfer and continuity of care. The Canadian journal of nursing research $=$ Revue canadienne de recherche en sciences infirmieres. 2004;36(2):89.

66. Wagner C. Wiki: A technology for conversational knowledge management and group collaboration. Communications of the Association for Information Systems. 2004;13(19):265-289.

67. Oborn E. Facilitating implementation of the translational research pipeline in neurological rehabilitation. Current opinion in neurology. 2012;25(6):676-681.

68. Jette DU, Bacon K, Batty C, et al. Evidence-based practice: beliefs, attitudes, knowledge, and behaviors of physical therapists. Physical Therapy. 2003;83(9):786-805.

69. Jones ML, Cifu DX, Backus D, Sisto SA. Instilling a research culture in an applied clinical setting. Archives of physical medicine and rehabilitation. 2012.

70. Grimmer - Somers K, Lekkas P, Nyland L, Young A, Kumar S. Perspectives on research evidence and clinical practice: a survey of Australian physiotherapists. Physiotherapy Research International. 2007;12(3):147-161.

71. Bayley MT, Hurdowar A, Richards CL, et al. Barriers to implementation of stroke rehabilitation evidence: findings from a multi-site pilot project. Disability and Rehabilitation. 2012;34(19):1633-1638. 
72. Bridges PH, Bierema LL, Valentine T. The propensity to adopt evidence-based practice among physical therapists. BMC health services research. 2007;7(1):103.

73. Corcoran M. Dissemination or knowledge translation? 2006.

74. Lloyd C, King R, Bassett H. Occupational therapy and clinical research in mental health rehabilitation. The British Journal of Occupational Therapy. 2005;68(4):172-176.

75. Pollock AS, Legg L, Langhorne P, Sellars C. Barriers to achieving evidence-based stroke rehabilitation. Clinical Rehabilitation. 2000;14(6):611-617. 